\title{
A Reportagem em contexto de Jornalismo de Proximidade
}

\author{
Tatiana Melo \& Telmo Silva \\ Universidade de Aveiro \\ E-mail: tatianabentomelo@gmail.com/tsilva@ua.pt
}

\begin{abstract}
Resumo
Neste artigo pretende-se demostrar o importante papel que o jornalismo de proximidade ocupa numa sociedade marcada pela globalidade. Procura-se, ainda, analisar as potencialidades da televisão enquanto meio de comunicação ao serviço de uma comunidade e da reportagem enquanto género jornalístico de referência. Nesse sentido serão apresentas as reflexões preliminares de uma investigação

nalismo de proximidade, utilizando como estudo de caso as reportagens realizadas no Porto Canal.

Recorrendo à observação participante como método de recolha de dados, o investigador pretende traçar as guidelines para a construção de uma reportagem neste contexto, atendendo às três fases pela qual passa durante a sua construção: Produção; Realização e Pós-produção.
\end{abstract} sobre a reportagem em contexto de jor-

Palavras-chave: jornalismo de proximidade; televisão; reportagem, região.

\begin{abstract}
This article aims to demonstrate the important role of local journalism in a society marked by globality. The goal is also to analyze the potential of television as a means of communication servicing a community and the report as a journalistic genre of reference.

Therefore, preliminary reflections of an investigation will be presented about the

using the reports made in Porto Canal as a case study.

By resorting to the participative observation as a method of data collection, the investigator aims to set the guidelines for the construction of a report in this context, taking into account the three phases which it goes through: Production, Directing and Post-Production.
\end{abstract} report in a context of local journalism,

Data de submissão: 2016-05-10. Data de aprovação: 2016-05-22. 
Keywords: local journalism; television; report; region.

\section{Introdução}

TUALMENTE as sociedades estão organizada de uma forma em que a inA formação ocupa um papel determinante. Os indivíduos que as constituem demonstram curiosidade acerca dos acontecimentos e gostam de expressar o seu parecer sobre os mesmos. Assim, recorrem aos media de forma a obterem todos os dados necessários à formulação dessa opinião.

"Ao longo dos séculos, as pessoas têm desejado ser informadas sobre o que as rodeia, usando o jornalismo para se manterem em dia com os últimos acontecimentos, para os combinarem com um conhecimento do tópico que lhes permita participar em conversas pessoais e de grupo" (Traquina, 2002,p.10).

Em Portugal a importância dada à informação pode ser facilmente constatada ao verificamos que todos os canais generalistas nacionais têm também um canal temático, capaz de oferecer ao público um horário mais alargado de conteúdos informativos - SIC Notícias; RTP3 e TVI 24.

De um modo geral, esses conteúdos podem ser difundidos em diversos meios, com características completamente distintas - Imprensa; Rádio e Televisão. No entanto, e apesar de no seu surgimento ter vivido durante alguns anos à sombra da rádio, e de atualmente ter que lidar com a utilização da Internet como veículo de informação, a televisão continua a ser o meio de comunicação de excelência. O imediatismo e o facto de associar som e imagem, permitindo ao telespectador realizar simultaneamente outras tarefas, têm-se revelado características fundamentais para a seleção deste meio em detrimento de outros.

Quanto às escolha do conteúdo ao qual se pretende assistir, o telespectador prefere aquele que se relacione com os seus interesses pessoais. Este pode ser condicionado por diversos fatores, no entanto, um deles é, normalmente, consensual: a proximidade. Essa proximidade não se refere simplesmente ao espaço geográfico, é um fenómeno que vai mais além e que envolve a vertente social, temporal e psicoafectiva, traduzindo-se no sentimento de pertença a determinada comunidade. 
De forma a garantir a difusão de informação de proximidade surgiu uma diferente forma de fazer jornalismo, levada a cabo por meios que se "dirigem a uma comunidade humana de tamanho médio ou pequeno, delimitada territorialmente, com conteúdos relativos à sua experiência quotidiana, às suas preocupações e aos seus problemas, ao seu património linguístico, artístico e cultural e à sua memória histórica" (Moragas as cited in Coelho, 2005, p. 154).

Assim sendo, ao compreender a importância da televisão como meio de divulgação e dos conteúdos de proximidade como elementos de construção de identidade, associados à comunidade em que estamos inseridos, é possível entender a pertinência do estudo sobre o jornalismo de proximidade praticado pela televisão.

Quanto à forma como a informação chega ao público, esta é apresentada em vários formatos, assumindo todos eles uma importância diversificada no jornalismo. Porém, um dos géneros mais relevantes é, sem dúvida, a Reportagem.

A construção da reportagem obriga o profissional a um conhecimento mais aprofundado de determinado tema e permite a inclusão de outros géneros dentro de si própria, como é o caso da entrevista, tornando-se, por isso, um género muito completo.

Consciente da importância da reportagem em jornalismo, na presente investigação pretende-se perceber o que se deve ter em conta no desenvolvimento da mesma, em contexto de jornalismo de proximidade.

\section{Jornalismo de Proximidade}

O jornalismo enquanto conceito surge associado ao dever de informar, ao imediato, à tarefa de espelhar a realidade e acima de tudo a um valor fulcral de uma sociedade democrática: Liberdade.

Traquina (2002) entende que "pode ser visto como a vida em todas as suas dimensões, como uma enciclopédia" (p.9). Silva (2010), por sua vez, define-o "como um conjunto de técnicas, baseado no imediatismo e depende intimamente dos acontecimentos sociais" (p.1).

Ao aliar este conceito à ideia de proximidade, surge um diferente modo de comunicação. Um jornalismo baseado numa forma de informar pensada 
e destinada para um público específico, onde a proximidade e a noção de território comandam o discurso.

Quando se pensa em informação de proximidade, assume-se uma relação entre os media e os recetores da informação, uma relação baseada no interesse comum. Esse interesse reflete-se no cidadão quando espera que determinado assunto seja abordado pelo media e no media quando escolhe determinada temática que pensa ter mais audiência por parte do público. Neste sentido, Raimundo (1991) considera que "a lei da proximidade" em informação nasce "da preocupação de conquistar as boas graças do público, através da criação de cadeias de cumplicidade" (p.70). Essa proximidade pode assumir quatro vertentes: geográfica; temporal; psicoafectiva e social. E são "os laços de proximidade resultantes dessas vertentes que são capazes de determinar a audiência" (Camponez, 2002, p.118).

No entanto, e apesar das restantes formas de refletir a proximidade não serem totalmente descartadas, no caso dos meios de comunicação regionais a vertente geográfica assume um papel primordial.

A região onde determinado meio se insere marca, assim, todo o seu funcionamento - desde a escolha das temáticas a abordar, o enfoque que é dado e, consequentemente, a mensagem transmitida. $\mathrm{O}$ território aparece em primeiro lugar, e se a notícia se refere a algo que ultrapassa esse espaço, é analisado o impacto local que a mesma poderá ter.

Esta orientação é defendida por Gerbaud (1996) na análise que faz sobre a imprensa local francesa, para quem "O jornal local estabelece uma relação mais convivial e calorosa, onde o jornalista tem o dever de informar: em primeiro lugar, sobre o que está à sua volta, de seguida sobre o que se passa no seu país e, finalmente, sobre o mundo.” (p.10-11)

Também Carlos Camponez, em Jornalismo de Proximidade, abordando o caso da imprensa regional, dá uma grande importância ao território, ao afirmar que esta o escolhe "como o lugar de realização do seu empenhamento: editorial, cultural, discursivo, económico". (Camponez, 2002, p.273).

O mesmo autor entende que "a proximidade pode ser geradora do que denominamos por comunidade de lugar. $\mathrm{O}$ conceito reporta-se a uma proximidade situada localmente, num espaço e num tempo territorialmente identificados". (p.20)

Essa comunidade, quando atribuída às reflexões de Robert Boure e Alain Lefebvre (2000, p. 270), é descrita como "lugar específico que se distingue 
dos outros lugares pelas singularidades ligadas à origem, à sua construção, mas também à sua localização no espaço".

Posto isto é possível perceber a importância dada ao aspecto geográfico. No entanto, este surge interligado com as restantes vertentes, nomeadamente a social. Puente (as cited in Camponez, 2002, p.119) reforça a ideia ao afirmar que "a proximidade tem a ver também com as realidades sociais que nos rodeiam, os serviços de que dispomos na nossa vila ou aldeia".

Atualmente, o modo como os media difundem a informação e nos aproximam das situações, independentemente da distância a que estas acontecem, levam-nos à ideia de "Aldeia Global" defendida por Mc Luhan, segundo a qual o mundo se traduz numa pequena aldeia, em que todos se conhecem. Neste contexto, surgem dúvidas em relação ao modo como se pode destacar uma região. Materializando a questão, perguntamo-nos: Como somos capazes de dotar de interesse uma informação que aborda assuntos ligados a uma região quando as fronteiras parecem tender a desaparecer? A resposta passará pelo sentimento de pertença e pelos laços sociais criados. Estes devem ser reforçados de forma a conduzir à criação de uma identidade regional. E chegados à "aldeia global concluímos que a única coisa que nos diferencia na verdade é a nossa aldeia" (Puente as cited in Camponez, 2002, p.120). Assim sendo, conclui-se que o conceito de região não se limita, simplesmente, ao aspeto físico. A região é "sobretudo uma relação entre pessoas, um espaço de apropriação e de identificação, uma construção social permanente" (Ramirez as cited in Coelho, 2005, p.153).

Nessa região os media ocupam um papel determinante. Por um lado, devem ser os responsáveis pela prática da comunicação, vista como "a base que torna possível a interação entre os diversos atores sociais que ocupam o território de determinada região" (Coelho, 2005, p.153). Por outro lado, devem reforçar os laços sociais e o sentimento de pertença, de modo a criar a identidade regional. Para Carlos Camponez, analisando o caso particular da imprensa regional, a razão de ser deste meio de comunicação baseia-se "no próprio pressuposto da existência de um espaço público ligado pela identidade, à qual pretende dar voz e, por essa via, reforçar os sentimentos de pertença" (Camponez, 2002, p.29).

João Carlos Correia reforça esta ideia ao defender que "a definição de um campo jornalístico regional deve ter em conta que a identidade de regiões 
comporta a necessidade de mecanismos de produção simbólica que comtemplem o reforço do sentimento de pertença". (Correia, 1998, p.161)

Ou seja, a criação da identidade regional pode ser considerada como uma das principais funções dos meios de comunicação regionais e locais. Coelho (2005) defende que a identidade regional é "o motor da região", e a maneira como cada região a encara condiciona a criação de meios e até mesmo o desenvolvimento da própria região:

"As regiões com forte grau de identidade esforçam-se por preservar e reforçar o conjunto de elementos que as distingue das demais, para tal exigem a criação de meios de comunicação social próprios. Entre os meios de comunicação social e a região estabelece-se, assim, um pacto que tem como princípios básicos o reforço da identidade regional e o desenvolvimento da própria região." (p.153)

Esse pacto comunicacional - Pacto de Proximidade - assumido entre os media e os que constituem a comunidade, tem como principal objetivo "defender a região e as gentes em nome do desenvolvimento" (Coelho, 2005, p.153).

Aqui, ambos desempenham um importante papel. Os media são responsáveis por dotar de informação os membros da comunidade, ao abordar os temas que lhes despertam um maior interesse, ouvindo as diferentes opiniões dos seus participantes. A comunidade, por sua vez, deve dar aos media as condições necessárias para a produção de conteúdos, como a partilha de informações que considerem relevantes. Ou seja, os meios de comunicação e os membros da comunidade devem atuar em conjunto pelo sucesso da região. Para Carlos Camponez é neste compromisso que "se frutifica ou fracassa, se diversifica ou homogeneíza a comunicação". (Camponez, 2002, p.103)

Com este acordo, mais do que divulgar uma região enquanto um espaço físico, pensa-se no seu desenvolvimento social e só os media que forem capazes de o seguir conseguem cumprir a função social que lhes é atribuída.

No exercício desta função, espera-se que os meios de proximidade, pelas suas características, sejam capazes de promover o debate, que ofereçam opiniões contraditórias sobre a mesma situação, apelando à construção de um espaço público que dê primazia ao uso da razão. 
João Carlos Correia (1988) reforça esta ideia ao considerar que o jornalismo local pode ser um "elemento estruturador desse espaço público regional entendido como esfera crítica de debate e de interação dos cidadãos em torno dos problemas que lhes são mais próximos" (p.156).

Para Blumler e Gurevitch (as cited. in Coelho, 2007) é possível reconhecer a função social, no caso das televisões de proximidade:

"Quando estes media se transformam nos vigilantes do espaço público, no sentido em que fiscalizam o poder e os seus representantes, criticando-os, se tal for necessário, ou iluminando o caminho de todos os que participam nesse exercício. O cumprimento dessa função social determina, igualmente, que, ao mesmo tempo que esses media dotam os cidadãos dos instrumentos que lhes permitem questionar a política e os políticos, favorecem a participação desses destinatários no processo de tomada de decisão, contribuindo para atenuar, por isso mesmo, o fosso que os separa da elite." (p.322)

No entanto, no exercício deste jornalismo tão ligado ao território e à comunidade que a ele pertence, são vários os desafios e entraves encontrados. No que respeita aos desafios, estes passam pela capacidade de fazer uma adaptação ajustada de informações nacionais à realidade local; assumir um papel que o distinga em relação aos generalistas; fazer uma utilização inteligente dos meios de difusão e ser capaz de ultrapassar fronteiras, aproveitando, para isso, a comunidade emigrante.

Para a adaptação da informação, os meios de proximidade assumem a estratégia de captar a atenção da audiência para algo exterior, mostrando como isso os pode afetar. Aqui, o local assume-se como o "espaço de concretização das estratégias globais: o lugar de transformação dos particularismos numa cultura global" (Camponez, 2002, p.59).

Ao analisar o global, pretende-se mostrar como os meios locais devem ser capazes de se diferenciar dos nacionais. Por um lado, Correia (1998) defende que a Comunicação Social Regional Portuguesa apresenta "alguns traços típicos do jornalismo pré-industrial", ao contrário da Comunicação Social Nacional, onde "já se verificou todo o ciclo de industrialização do jornalismo, que coincide com a formação de um tipo de empresas especializadas" (p.157). Por outro lado, o mesmo autor encontra como fator distintivo a forma de interação 
entre os media e as audiências. No jornalismo regional a "interação é face a face", onde "os públicos devido à sua proximidade com as empresas jornalísticas, contaminam a produção informativa com a forma como sentem a sua vivência quotidiana". Nos meios nacionais assiste-se "a uma forte estereotipização do produto informativo que incide nalgumas instâncias centralizadas de funcionamento do campo político." (p.158-159)

O jornalismo industrializado, com uma grande preocupação com a maximização das audiências, que caracteriza os meios nacionais, põe em causa a já referida função social que se espera dos meios de comunicação. E é no bom desempenho desta função que os meios de comunicação de proximidade se podem destacar, aproximando-se do público através da primazia da utilização da razão e do debate em detrimento da lógica de mercado.

A utilização inteligente dos meios de difusão por parte do jornalismo de proximidade é outro dos desafios que este encontra. Aqui a internet aparece como a solução ideal para ultrapassar a barreira da televisão por subscrição, e também como meio de divulgação de conteúdos para fora do país. Isto acaba por aproximar a comunidade imigrante da sua região, ao mesmo tempo que conduz à expansão do canal.

Aquando a tentativa de responder aos desafios aqui enumerados, os meios de proximidade encontram fortes entraves.

Um desses limites é a forte dependência dos meios para com as elites, em busca de apoio financeiro: "Em mercados pobres, como a maior parte dos mercados regionais portugueses, afrontar os escassos anunciantes, sejam eles empresas da região, associações, organismos do Estado, ou autarquias, que participam no processo através da publicidade institucional, é assumir o fim da publicação." (Coelho, 2005, p.160).

Surge, assim, a necessidade de perceber como se consegue desenvolver a função social, num meio marcado pela dependência por fatores económicos e aproximação ao poder político.

Para o autor de a TV de Proximidade, a solução passa pela criação de "modelo alternativo: a televisão de proximidade", onde os profissionais garantam o progresso da comunidade "mas sem perderem o distanciamento crítico que os coloca no papel de mediadores do espaço público e os transforma em agentes formadores da opinião pública crítica e esclarecida" (Coelho, 2007, p.320-321). 


\section{A Televisão como Meio de Informação Regional}

Apesar da televisão em Portugal surgir muito mais tarde, em 1956, globalmente um dos principais passos foi dado pela BBC, a 2 de Novembro de 1936, ao tornar sistemática a emissão de imagens em movimento à distância.

No entanto, inicialmente a televisão enfrentou sérias dificuldades. No contexto global, viu na segunda guerra mundial e nos conflitos militares característicos do século XX um imponente entrave, em Portugal o mesmo se verificou com o regime salazarista.

Porém, apesar de no início ter sido difícil o seu desenvolvimento, quando esta começou a ser utilizada de forma recorrente, rapidamente se percebeu o potencial que detinha, o verdadeiro poder da televisão.

Inicialmente, existiu a necessidade de fazer comparações de forma a perceber o que este meio podia trazer de novo. Mas as conclusões sustentam o determinante papel que a televisão assume nos dias de hoje: "se acontece que um tema - uma questão, um debate - seja lançado pelos jornalistas da imprensa escrita, só se torna determinante, central, quando é retomado, orquestrado pela televisão". (Bourdieu, 2005, p.53)

Aqui a imagem assume o papel principal e esta forma diferente de comunicar um acontecimento torna-se essencial para fortalecer o poder da televisão. Para Mc Luhan "o ouvido é intolerante, fechado e exclusivo, enquanto o olho é aberto, neutral e associativo" (as cited in Godinho 2011, p.32). Pierre Boudieu (2005) defende que "a imagem tem a particularidade de poder produzir aquilo a que os críticos literários chamam o efeito do real, de poder fazer ver e fazer crer no que se faz ver" (p.14).

A componente social que a televisão apresenta é, também, uma característica que demonstra a importância do meio para a sociedade. O facto de esta mostrar aquilo que quer contar diminui a distância a que determinado acontecimento decorre, elimina fronteiras, e faz-nos viver a situação descrita.

Deste modo, após analisar a informação de proximidade e constatar o poder da televisão, conclui-se que são grandes as vantagens em colocar ao serviço de uma comunidade um meio de comunicação tão influente. Para Rebelo (2010) "nenhum outro meio poderá, eventualmente, assumir-se como tão poderoso mobilizador dos espaços públicos regionais, no robustecimento da cidadania e comunhão na região/local." 
Quanto à importância da informação de proximidade num mundo marcado pela globalização e pelos conteúdos generalistas, Paulo Couto, em entrevista ao Diário de Notícias, sintetiza: "é preciso que alguém vá ao fim da rua já que as televisões convencionais vão ao fim do mundo" (DN, 2006).

No que ao surgimento das televisões regionais diz respeito, é importante referir que em Portugal estas surgiram mais tarde do que na restante Europa, que tiveram como fator impulsionador o surgimento da transmissão por cabo e que durante muitos anos atuaram sem qualquer base legal, o que terá sido determinante para acentuar a fragilidade do meio.

Segundo Coelho (2005) podem ser atribuídas duas razões que provocaram o atraso no surgimento de televisões regionais em Portugal: "por um lado, o elevado défice da RTP, que desincentiva o Estado de investir na televisão regional; por outro lado, a fragilidade dos mercados regionais que impede a recuperação económica do investimento, afastando do sector igualmente os privados." (p.172)

Inicialmente, a história das televisões regionais portuguesas é marcada pelo aparecimento de canais pirata. Loures, Sintra, Guimarães, Porto e Coimbra foram algumas das cidades, onde se verificou o aparecimento daqueles que para Mota (2005) foram "projetos voluntariosos e persistentes, que em alguns casos tiveram um impacto significativo nas populações a que ser dirigiam, inclusive com o apoio tácito dos políticos locais" (p.120).

No entanto, estes canais não passaram de experiências com um curto ciclo de vida, sendo a RTP Açores e RTP Madeira, resultantes do processo de descentralização da televisão pública, os primeiros canais a ser identificados como de carácter regional.

Com o aparecimento da televisão por cabo, em 1994, reuniram-se as condições que se pensavam ser as ideais para a proliferação de canais regionais. No entanto, este processo fez-se com algumas dificuldades.

Os primeiros canais de âmbito regional que surgiram no cabo foram a CNL e a NTV. Porém, não veicularam durante muito tempo informação regional. O CNL passado cerca de um ano da sua fundação foi comprado pela Impresa, grupo que detém a SIC, e dá origem ao primeiro canal de notícias português: Sic Notícias. A NTV deu lugar à RTPN, que, com o passar do tempo, foi perdendo a componente regional, tornando-se cada vez mais num canal de notícias de cobertura nacional, sendo atualmente a RTP3. 
Só em 2006 é que se volta a ouvir falar de televisões regionais, com a criação da Invicta TV e do Porto Canal. A Invicta TV, atual Regiões TV, passou por vários processos que se traduziram na alteração dos formatos e designação do canal. O Porto Canal, conta como marcos importantes da sua história a parceria com o FC Porto e a abertura de várias delegações que permitiram uma melhor cobertura de toda a região norte.

$\mathrm{Na}$ verdade a criação deste género de televisões enfrentou diversos entraves, dos quais se destacam a falta de financiamento e a inexistência, durante um longo período, de uma base legal que legitimasse a criação de órgãos de televisão de cariz regional.

A forma de financiamento de um meio regional deriva, normalmente, de subsídios públicos, da publicidade que conseguem trazer para o meio ou de investimento de privados. Quanto à legislação do meio, tal só viria a acontecer com a aprovação da Lei da Televisão, em 2007, onde surgem pela primeira vez regulamentadas as televisões regionais.

Em suma, a história dos meios regionais e locais é marcada por várias dificuldades que limitaram o desenvolvimento dos mesmos, levando em muitos casos ao seu encerramento.

O Porto Canal surge, neste contexto, como um exemplo de um órgão que conseguiu superar esses obstáculos, continuando a afirmar-se, atualmente, como um meio de proximidade. A ideia surge reforçada na notícia lançada pelo canal, a 18 de dezembro de 2015, onde apresenta, para 2016, o surgimento de "um Porto Canal renovado, mais forte e mais próximo", mantendo a filosofia "de canal generalista, informativo, formativo, de entretenimento e serviço público, focado no Mundo que é o território”.

\section{Reportagem de Proximidade}

A reportagem surge com uma forte ligação à literatura e assume-se nas décadas 20 e 30 do século XX, como um género em expansão. Contudo, a sua época gloriosa foi interrompida pela segunda grande guerra e mesmo após o seu término teve enormes dificuldades em implementar-se novamente, o que só viria a acontecer nos anos 60 .

No caso da reportagem televisiva e no contexto português, esta surgiu com o aparecimento da RTP. Porém, com técnicas bastante distintas das atuais, nomeadamente o facto de só o operador de câmara se dirigir ao local, ficando 
o jornalista na redação. Isto fazia com que houvesse um desfasamento entre o acontecimento e aquilo que era mostrado ao público, uma vez que aqueles que presenciavam a situação não eram os que a narravam: "Os redatores muitas das vezes já tinham o texto escrito antes de o acontecimento ter lugar. Escreviam-no com base em informações de agenda ou em telefonemas prévios. Eram raras as vezes em que adequavam os textos às imagens" (Godinho, 2011, p127).

Atualmente isto já não se verifica. A reportagem dá ao jornalista o papel de destaque, é ele quem conta pelas suas palavras aquilo que viu, enriquecendo-a com o uso de texto, som ou imagens, consoante o meio para o qual é pensada.

Analisando aquilo em que consiste este género jornalístico, considera-se bastante interessante a visão de Maria Cecília Guirado, que entende a reportagem como a arte de investigação, explicando o que sustenta esta definição.

Para a autora "É da natureza da reportagem revelar a origem e o desenrolar da questão que ela retrata. Assim, de alguma forma, a reportagem reponde, ou busca responder - em tese - aos interesses sociais." No que respeita à componente artística esta deve-se "ao processo de criação, pois envolve observação, investigação e construção de texto, que, embora distante do literário, não deixa de exigir do repórter habilidades especiais para perceber, traduzir e manusear palavras que reproduzem a realidade". Por fim, a associação à investigação é justificada pelo facto de considerar que "todos os repórteres são investigadores, pois todos estão, ou deveriam estar, em busca de informações surpreendentes. A investigação possibilita o acesso aos dados essenciais do acontecimento, aos detalhes, aos pormenores reveladores" (Guirado, 2004, p.22-23).

Ao adaptar a reportagem à televisão, acredita-se que, assim, se consegue oferecer ao público uma visão diferente de determinado acontecimento. A televisão consegue mostrar aquilo que narra e despertar, por isso, sensações por parte de quem assiste. Para Godinho (2011) "a reportagem televisiva, feita a partir de sons e imagens de acontecimentos reais, é uma obra que parte de um acontecimento para construir uma experiência própria" (p.43).

A imagem é assumida pelo repórter televisivo como a principal arma, mas não deverá ser tida como única. A inteligente articulação entre a imagem e o som, mais concretamente a voz-off, poderá ser determinante para o sucesso do produto final. 
No caso da reportagem de proximidade a identificação assume uma grande dimensão. O conteúdo é produzido para pessoas que têm uma relação de proximidade com aquele acontecimento, e que, deste modo, se vão sentir identificadas com aquilo que estão a ver. Isto acaba por criar grande pressão sobre o jornalista, uma vez que está a divulgar informação para um público que tem com aquele acontecimento o sentimento de pertença, tão característico dos meios de proximidade.

Também a experiência que a reportagem proporciona ao telespectador, que segundo Godinho é o fator de distinção deste género - "o próprio da reportagem é reportar, é assegurar uma "experiência" ao espectador "dentro" das imagens" (p.73) - acaba por estar condicionada com a ligação que o público mantém com o acontecimento.

Assim sendo, considera-se que o impacto que determinado conteúdo tem na audiência é um dos principais fatores a ter em conta no desenvolvimento da reportagem neste contexto. Esta deve ser capaz de oferecer ao público informação relevante, ao mesmo tempo que provoca uma agradável experiência.

A edição de imagem feita pelo próprio jornalista é outro dos fatores distintivos das reportagens de proximidade. Embora os canais informativos nacionais também já pratiquem esta filosofia do jornalista/editor no que respeita às pequenas peças de informação, normalmente a edição da reportagem é deixada a cabo do editor de imagem.

A edição é assim a altura em que o jornalista escreve com as imagens. Após a análise do acontecimento, da deslocação ao local para recolher toda a informação pertinente, é o jornalista que dá continuidade ao processo e constrói o produto final. Esta técnica assume grande importância pelo facto de permitir que exista um fio condutor que nunca é quebrado. É a visão do jornalista que investigou o caso que é traduzida nas imagens e não a do editor de imagem.

No caso dos meios de proximidade isto torna-se determinante, uma vez que foi o jornalista quem criou com os intervenientes os laços sociais anteriormente referidos nesta investigação, sendo, por isso, a pessoa indicada para construir na integra um conteúdo que veicule informação de proximidade.

Existe, porém, um fator que se pode demonstrar limitador no exercício da reportagem em jornalismo de proximidade: o elevado investimento que este género exige. 
Se a nível nacional se levantam questões de ordem económica na realização da reportagem, num contexto em que a publicidade é escassa e existe uma grande dificuldade na obtenção de rendimentos, o investimento torna-se um entrave determinante para a correta construção do género.

Embora um jornalista regional não tenha necessidade de investir tanto tempo, pelo facto de, normalmente, estar próximo dos acontecimentos de interesse para o público para quem trabalha, a exigência do ponto de vista de recursos humanos na elaboração destes conteúdos torna-se, por vezes, insuportável.

A reportagem é um género jornalístico, que exige na sua construção um trabalho em equipa. Se por um lado, como já verificamos, o jornalista é também responsável pela edição, não necessitando de um editor de imagem, por outro lado, este não dispensa o acompanhamento do repórter de imagem, responsável pela recolha de conteúdos visuais. Isto é, para cada acontecimento estarão, pelo menos, destinadas duas pessoas, não podendo uma reportagem ser ilustrada por imagens de arquivo, como acontece com a notícia.

No entanto, é de destacar que apesar destes entraves a reportagem continua a marcar presença nos noticiários dos meios de proximidade, o que demonstra a importância do género para a informação, justificando, assim, o investimento.

\section{Estudo de Caso}

Esta investigação tem como principal objetivo perceber como o contexto pode influenciar a construção audiovisual, mais concretamente a reportagem enquanto produto jornalístico de referência. Porém para atingir esta meta será necessário compreender tudo o que envolve a criação de um produto audiovisual de informação neste contexto específico.

Nesse sentido, e para conseguir atingir o proposto objetivo, entende-se que se terá de passar por várias etapas. Isto é, será necessário atingir, individualmente, os objetivos relacionados com o meio, o contexto e o produto audiovisual.

No que ao meio diz respeito - a televisão - é determinante perceber a importância que este tem para o jornalismo e como as suas características condicionam a construção de uma peça informativa. Quando um conteúdo é pensado para ser difundido pela televisão, este deve ser criado consoante um 
conjunto de regras que o diferem dos restantes meios, e é essa percepção de diferença, mas ao mesmo tempo de importância que a televisão tem para o jornalismo, que se pretende ver consolidada.

Relativamente ao contexto em que este produto é construído, isto passa essencialmente por perceber como este pode influenciar a produção de informação. Se por um lado a proximidade poderá funcionar como um limite à liberdade jornalística ou, por outro lado, como um aliado à obtenção de informação.

Quanto ao produto audiovisual - a Reportagem - são várias as finalidades que se esperam ver cumpridas. Fundamentalmente pretende-se perceber o que distingue este género jornalístico dos demais, de forma a ser considerado o género nobre do jornalismo. Para isso, também é necessário clarificar os desafios e entraves que o jornalista encontra aquando a sua realização, acreditando que a investigação seja o principal desafio e a necessidade de investimento acrescido um importante entrave.

Em suma, perceber no caso especifico em estudo, o jornalismo de proximidade, que aspetos devem ser tidos em conta no desenvolvimento deste género jornalístico, tanto na recolha, na produção, como na difusão dos conteúdos.

De modo a conseguir cumprir os objetivos acima descritos, que culminam com a enumeração das guidelines da reportagem em jornalismo de proximidade, foi feito um estudo de caso sobre as reportagens realizadas pelo Porto Canal. A escolha deste órgão de comunicação prende-se com o facto de se considerar uma referência do jornalismo de proximidade no panorama nacional.

\section{Análise de Resultados}

Para o correto procedimento de análise de resultados considera-se necessário estudar individualmente cada fase de realização de uma reportagem audiovisual: Produção; Realização e Pós- Produção.

Assim sendo, a seguinte tabela apresenta exemplos práticos vivenciados pelo investigador aquando a sua presença no Porto Canal para a concretização do estudo, de forma a fundamentar as guidelines para a reportagem de proximidade que conseguiu identificar. 
$\bigoplus$

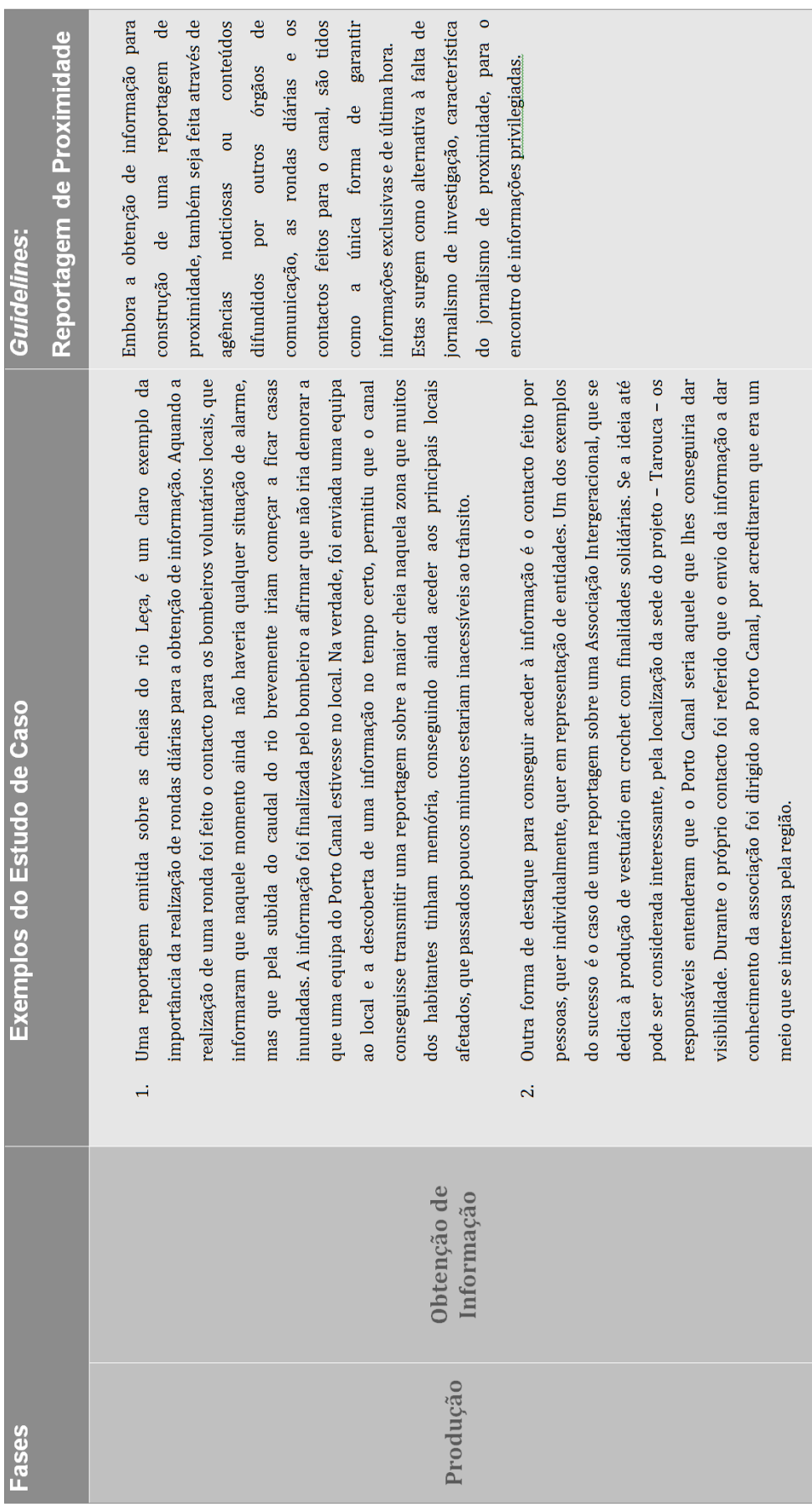


$\bigoplus$

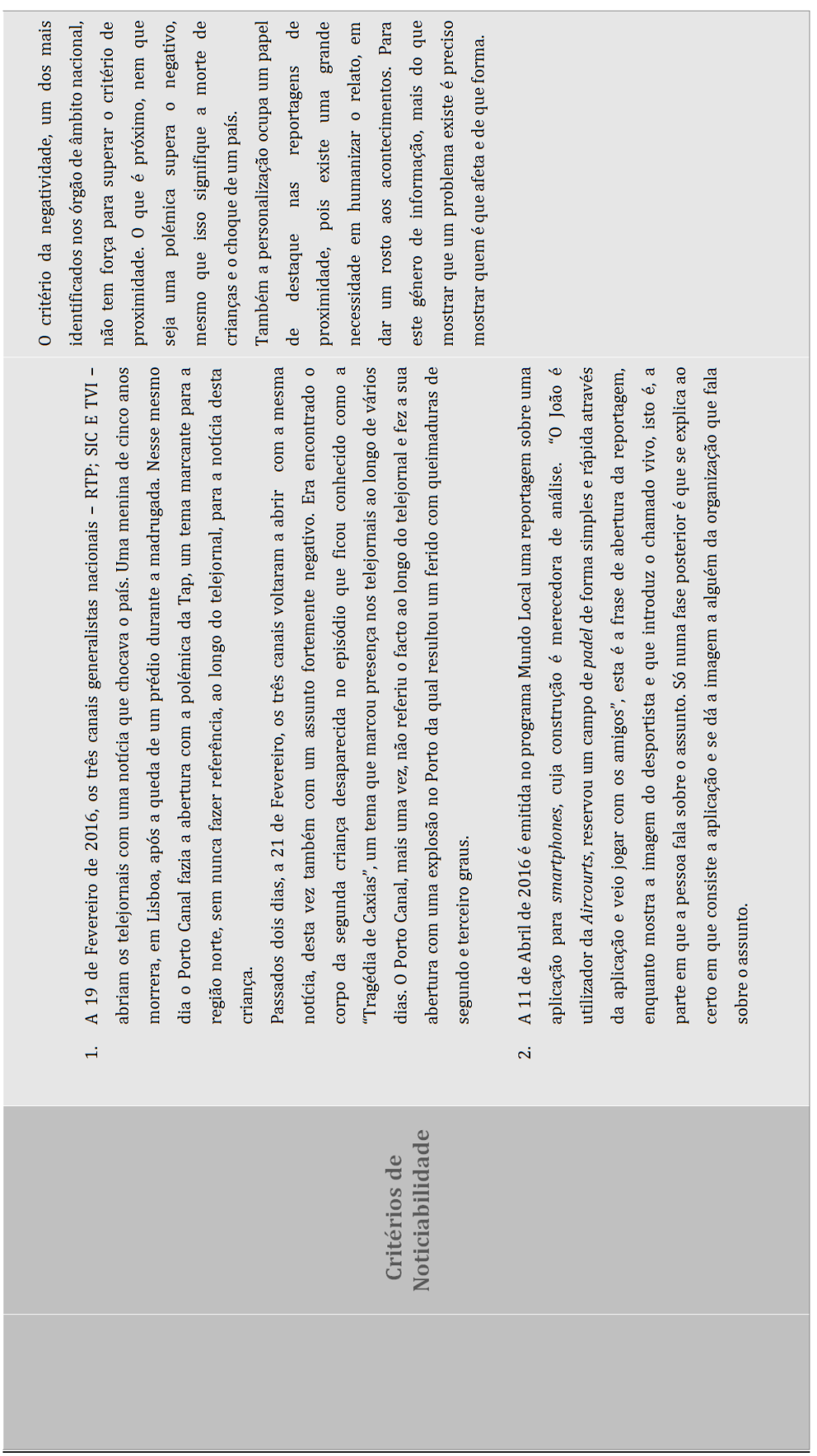


$\bigoplus$
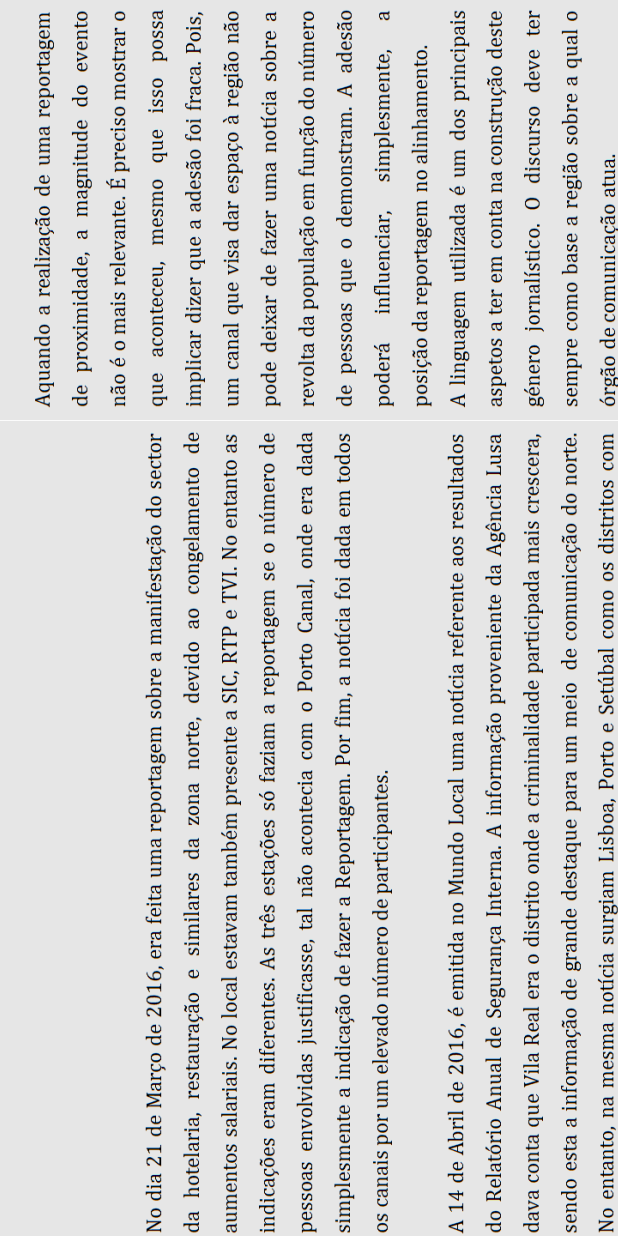

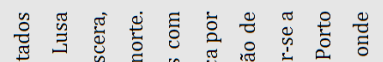

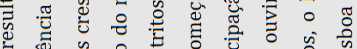

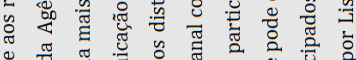

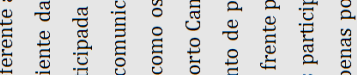

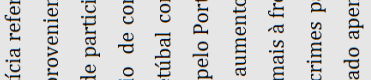

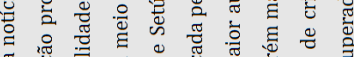

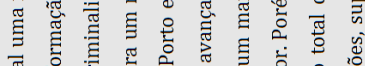

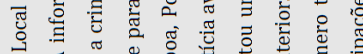

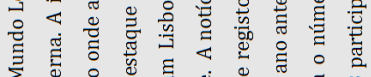

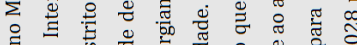

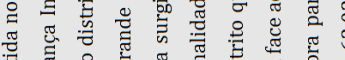

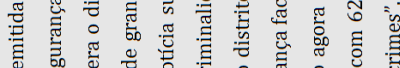

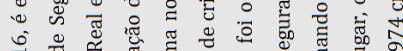

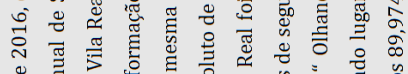

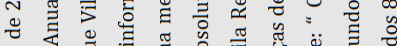
च

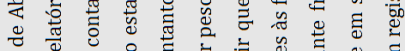

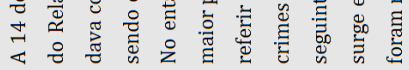


$\bigoplus$

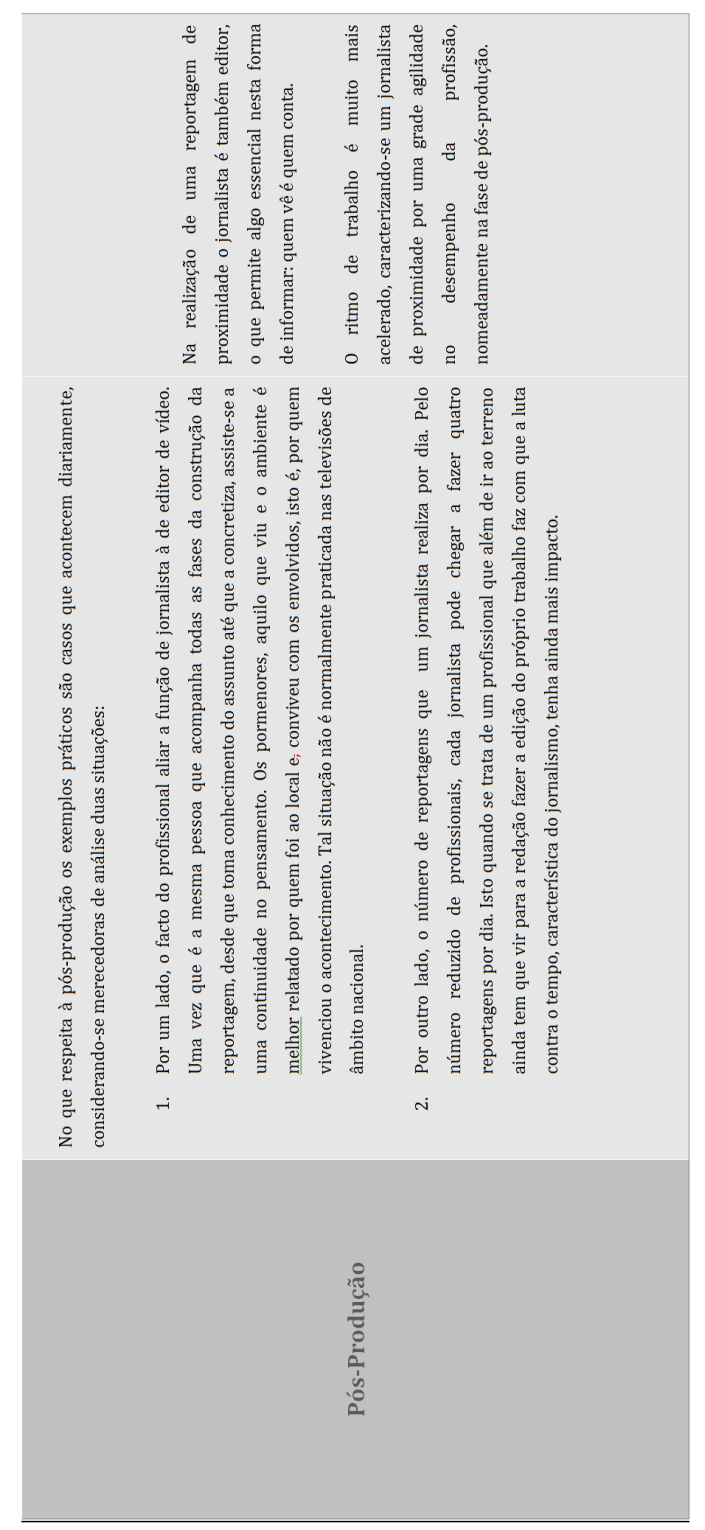




\section{Considerações finais}

A investigação desenvolvida permite perceber que o jornalismo de proximidade se rege por regras muito características que condicionam toda a sua atividade. Os profissionais que o praticam devem ser capazes de seguir os princípios éticos e deontológicos, mesmo quando a pressão financeira os desafia; devem conseguir criar uma identidade regional numa época que privilegia o global; devem cumprir uma função social, promovendo o debate e não a aceitação, por fim, devem ter como prioridade o território quando o assunto é o mundo.

Quando esta forma de informar se manifesta recorrendo a um meio de divulgação como a televisão todas estas características saem reforçadas. No entanto, apesar das vantagens enumeradas para a sua existência, as televisões de proximidade continuam a ter dificuldades em crescer. Neste sentido, surge como exemplo o caso do Porto Canal, um órgão que se assume como promotor de informação de proximidade, e de quem se espera ver cumprido o pacto de proximidade, isto é, veicular conteúdos informativos que deem voz e imagem aos cidadãos sempre com o mesmo propósito: o desenvolvimento da região.

Para esse efeito, a reportagem surge como o género ideal. Aquele que permite a aproximação do jornalista ao seu público, que o leva ao local e às suas gentes para contar aquilo que aconteceu.

Durante a realização de uma reportagem pensada para um público com quem se tem de criar laços de pertença, identificam-se regras de construção que a diferem das transmitidas nos meios de comunicação de âmbito nacional.

No que respeita à produção é preciso ter em conta que a única forma de obtenção de informações privilegiadas passa pela realização de rondas diárias - contactos com os bombeiros e serviços de segurança - e pelos contactos recebidos, quer individualmente, quer em representação de entidades. Aqui não há lugar para o jornalismo de investigação.

Depois de receber a informação é necessário proceder à seleção de forma a perceber se cumpre os requisitos para ser considerada de interesse noticioso. Nesse sentido a proximidade e a personalização dominam como critérios de noticiabilidade, ultrapassando a negatividade ou magnitude, valores notícia tão característicos dos meios de âmbito nacional.

Quanto à realização a noção de território deve estar sempre presente. Aquilo que se difunde e a forma como se faz deve ser sempre a pensar na- 
queles a quem se dirige. Ou seja, a linguagem utilizada a proximidade de tratamento, o sentir-se parte daquela comunidade é essencial para que uma reportagem de proximidade seja bem construída.

Por fim, em jornalismo de proximidade, o jornalista é também o responsável pela pós-produção. É a mesma pessoa que vai ao terreno presenciar o acontecimento, que conta a história em formato audiovisual e a entrega ao público.

Em suma, os diferentes procedimentos seguidos para a construção de um género jornalístico tão praticado em todos os meios de comunicação espelham o carácter único do jornalismo de proximidade.

\section{Referências Bibliográficas}

Bourdieu, P. (2005). Sobre a Televisão. Oeiras: Celta.

Boure, R. \& Lefebvre, A. (2000). Télévisions «locales» ET. n. 26, 27.

Camponez, C. (2002). Jornalismo de Proximidade. Coimbra: Minerva.

Canal, P. (2015). "Novo" Porto Canal nasce já dia 11 de Janeiro. Um Canal para SENTIR AINDA MAIS. Retrieved from http://portocanal.sapo.pt/noti $\mathrm{cia} / 77435 /$

Coelho, P. (2005). A TV de Proximidade e os Novos Desafios do Espaço Público. Lisboa: Livros Horizonte.

Coelho, P. (2007). FLP A função social das televisões de proximidade. Por um modelo de comunicação alternativo. Estudos em Comunicação, (1): 319-331.

Correia, J. (1998). Jornalismo e Espaço Público. Retrieved from http://www. livroslabcom.ubi.pt/pdfs/20110826-correia_jornalismo_espacopublico. pdf

DN. (2006). As televisões que vão ao "fim da rua" na Internet. Retrieved from http://www.dn.pt/arquivo/2006/interior/as-televisoes-que-vaoao-fim-da-rua-na-internet-641001.html

Gerbaud, D. (1996). La presse locale, facteur de cohésion sociale. Communication et Languages, (109): 10-11.

Godinho, J. (2011). As Origens da Reportagem - Televisão. Lisboa: Livros Horizonte. 
Guirado, M. (2004). Reportagem: a arte da investigação. São Paulo: Arte \& Ciência.

Raimundo, O. (1991). A Linguagem dos Jornalistas - Manual de escrita jornalística. Ericeira: O Acontecimento.

Rebelo, C. (2010). TV Local e alegação da sociedade civil, a diversidade e o pluralismo: o (não) caso português. Actas II Congresso Internacional Latina de Comunicación Social. Universidad de La Laguna.

Silva, R. (2010). A Transição do Jornalismo - Do Século XIX ao Século XX.

Traquina, N. (2007). Jornalismo. Lisboa: Quimera. 